\title{
NON-TARGET AND SECONDARY POISONING RISKS ASSOCIATED WITH CHOLECALCIFEROL
}

\author{
C.T. EASON ${ }^{1}$, M. WICKSTROM ${ }^{2}$, R. HENDERSON ${ }^{3}$, \\ L. MILNE ${ }^{1}$ and D. ARTHUR ${ }^{4}$ \\ ${ }^{1}$ CENTOX Centre for Environmental Toxicology, Landcare Research, \\ PO Box 69, Lincoln 8152, New Zealand \\ ${ }^{2}$ University of Saskatchewan, 44 Campus Drive, Saskatoon, SK S7N 5B3, Canada \\ ${ }^{3}$ Drains Road, Leeston, New Zealand \\ ${ }^{4}$ Labworks Laboratory, PO Box 113, Lincoln University, Lincoln, New Zealand
}

\begin{abstract}
In New Zealand cholecalciferol-containing baits are used for possum and rodent control. We have assessed the primary and secondary nontarget hazards associated with these baits. At $2000 \mathrm{mg} / \mathrm{kg}$ cholecalciferol had no adverse effects in ducks, but some chickens and canaries died. Weta and weka were not affected by eating bait containing cholecalciferol. In secondary poisoning studies most dogs and cats fed carcasses of possums poisoned with cholecalciferol were unaffected, but repeat exposures for 5 days induced some reversible signs of toxicosis in dogs. The most distinguishing feature of cholecalciferol is a lower risk of secondary poisoning when compared with 1080 and brodifacoum.
\end{abstract}

Keywords: vertebrate pesticide, cholecalciferol, non-target species, risk assessment.

\section{INTRODUCTION}

Cholecalciferol (Vitamin D3) was first used as a rodenticide in the 1980s (Marshall 1984). It was initially registered in the USA. In Europe it has been added to baits (containing first-generation anticoagulants) to overcome anticoagulant resistance in rats and mice (Tobin et al. 1993; Pospischil and Schnorbach 1994). In 1995 a cerealbased pellet containing cholecalciferol was registered for the control of brushtail possums (Trichosurus vulpecula) in New Zealand. Possum baits contain cholecalciferol at $0.8 \%$, approximately 10 times more active ingredient than in rodenticide formulations, to compensate for possums' larger sizes (Eason 1991).

Animals that ingest a lethal dose of cholecalciferol bait die usually within 4-7 days. Clinical signs commonly expressed include loss of appetite, constipation, lethargy and death. In order to gain biological and toxicological activity, cholecalciferol must undergo metabolic conversion to 25-hydroxycholecalciferol (25OHD). At toxic doses 25OHD disrupts calcium homeostasis by increasing its absorption from the small intestine and mobilisation from bones into the blood stream, as well as decreasing calcium excretion by the kidneys (Jolly et al. 1993; Beasley et al. 1997). Mineralisation and blockage of blood vessels, with death probably from heart failure, appears to be the mode of action of cholecalciferol in rodents and possums (Jolly et al. 1993). In other species, including cats and dogs, renal failure (caused by vessel blockage and nephrocalcinosis) and gastrointestinal haemorrhage appear more prominent (Haschek et al. 1978; Gunther et al. 1988; Moore et al. 1988; Jolly et al. 1993).

The single-dose $\mathrm{LD}_{50}$ for cholecalciferol in Norway rats $(42.5 \mathrm{mg} / \mathrm{kg})$ and house mice $(43.6 \mathrm{mg} / \mathrm{kg})$ is very similar, but there is some species variation in susceptibility amongst other mammals. Possums and rabbits are particularly sensitive to cholecalciferol (Eason 1991, 1993; Jolly et al. 1995). Cholecalciferol has also proved effective in the US in controlling rock squirrels, gophers and ground squirrels (Beard 
et al. 1988; Tobin et al. 1993), and is currently under investigation in New Zealand for the control of stoats (E.B. Spurr, pers. comm.). Cats are less susceptible than possums, and toxicity is less consistent, with some cats surviving doses up to $200 \mathrm{mg} / \mathrm{kg}$, while others died after doses of $50 \mathrm{mg} / \mathrm{kg}$ (Eason 1991). Some fish-eating marine mammals, such as seals, which are exposed to high dietary levels of cholecalciferol, are quite resistant (Keiver et al. 1988).

Because vitamin D3 is naturally occurring and involved in calcium homeostasis, there has on occasion been a tendency to consider baits containing cholecalciferol as safe to non-target species. In this paper we report data from acute toxicity studies in non-target species and secondary poisoning assessment in dogs and cats. The later, secondary poisoning builds on earlier work where Marshall (1984) showed no signs of toxicosis in dogs eating rodents killed with baits containing $0.015 \%$ cholecalciferol.

\section{Non-target acute toxicity}

\section{METHODS}

Non-target species were exposed as follows: groups of six mallard ducks (Anas platyrhyndos), four domestic chickens (Gallus gallus), and four canaries (Serinus canarius) were dosed orally with cholecalciferol concentrate at $2000 \mathrm{mg} / \mathrm{kg}$ in corn oil. Control groups received corn oil alone. Sixteen weka (Gallirallus australis) were allowed to voluntarily ingest bait containing $0.1 \%$ cholecalciferol (concentration similar to rodenticide formulations).

Two groups of six ground weta (Hemideina spp.) were orally dosed with cholecalciferol concentrate in corn oil at $125 \mathrm{mg} / \mathrm{g}$ and $250 \mathrm{mg} / \mathrm{g}$. A control group received corn oil alone. All animals in these acute toxicity studies were observed for 30 days after dosing, and clinical signs of poisoning and mortality noted.

\section{Secondary-poisoning feeding studies in cats and dogs}

Possums were chosen for the secondary-poisoning studies because the concentration of cholecalciferol in possum bait is more than 10 times greater than that used for rodents. Hence, possums poisoned with these baits are likely to provide a 'worst-case' scenario in terms of the potential secondary poisoning risks associated with use of rodent baits.

Twelve feral cats were fed whole carcasses of cholecalciferol-poisoned possums as their only food for 5 consecutive days. Appetite and body weight were monitored daily for 63 days, and blood samples were taken at regular intervals for serum calcium measurements, prior to the experiment and after the 5-day treatment period. Further blood samples were taken 1 and 7 weeks after cessation of treatment.

To assess the secondary poisoning risks to domestic dogs in a more comprehensive manner, six groups of dogs were fed tissue from cholecalciferol-poisoned possums or control meat (Table 1). Possums were divided into two groups and given an LD95 dose of cholecalciferol-treated cereal bait. The first group of possums was monitored until death occurred from poisoning (typically within 5-7 days). Dogs fed these carcasses were therefore exposed to the concentration of $250 \mathrm{HD}$ residues usually encountered by scavengers after possum-poisoning operations. In addition, in order to create a worst-case secondary poisoning scenario, a second group of possums was humanely killed $48 \mathrm{~h}$ after dosing with cholecalciferol. These carcasses would be expected to contain high levels of tissue 25OHD (Keiver et al. 1988; Dougherty et al. 1990), plus residual bait material in the gastrointestinal tract. Possums that were used as controls were undosed.

Twenty-two stray dogs, scheduled for euthanasia, were obtained from a pound and allocated to six different treatment groups (see Table 1). Dogs were fed one poisoned carcass for 1, 2 or 5 consecutive days. Control dogs were fed carcasses of undosed possums. Blood samples were collected from all dogs to monitor changes in serum calcium and urea nitrogen. Dogs were humanely euthanased after 14 or 28 days, and subjected to complete post-mortem and histopathological examination. Animal Ethics approval for these studies was obtained from the Landcare Research Animal Ethics Committee. 
TABLE 1: Dog treatment groups, animal numbers and mean dog body weights at the onset of dosing.

\begin{tabular}{lccc}
\hline Treatment & No. of carcasses & Mean body weight $(\mathrm{kg})$ & Sample size \\
\hline carcass (died) $^{1}$ & 1 & 15.3 & 2 \\
carcasses (died) $^{1}$ & 2 & 21.0 & 2 \\
carcasses (died) $^{1}$ & 5 & 20.2 & 6 \\
carcass (killed) $^{2}$ & 1 & 20.5 & 2 \\
carcasses (killed) $^{2}$ & 5 & 24.5 & 6 \\
undosed carcasses $^{3}$ & 5 & 20.5 & 4 \\
\hline
\end{tabular}

${ }^{1}$ Possums which died 5-7 days after dosing.

${ }^{2}$ Possums euthanased $48 \mathrm{~h}$ after dosing prior to death.

${ }^{3}$ Undosed possums gavaged with water only.

\section{RESULTS}

Mallard ducks were not affected by oral dosing with cholecalciferol at 2000 $\mathrm{mg} / \mathrm{kg}$. However, $25 \%$ (1/4) of canaries and $75 \%$ (3/4) of domestic chickens died following exposure to the same dose.

In the studies using native New Zealand non-target species, 10/16 weka ate bait containing $0.1 \%$ cholecalciferol. The maximum amount eaten by weka was $58 \mathrm{~g}$ of bait, while seven birds ate less than $10 \mathrm{~g}$. No weka exhibited signs of cholecalciferol toxicosis. There also appeared to be no treatment-related adverse effects in weta dosed orally with cholecalciferol (1/6 died in each group).

Each of the 12 cats ate approximately $1 \mathrm{~kg}$ of possum tissue containing residues of cholecalciferol over the 5-day period. No cats died, and at the end of 5 days, and in all subsequent samples, mean serum calcium concentrations remained within, or very close to, the normal range for cats (2.0-2.7 mmol/litre) (Table 2). This mild deviation is not clinically significant, as also evidenced by the lack of effect on appetite and body weight of treated cats (Fig. 1).

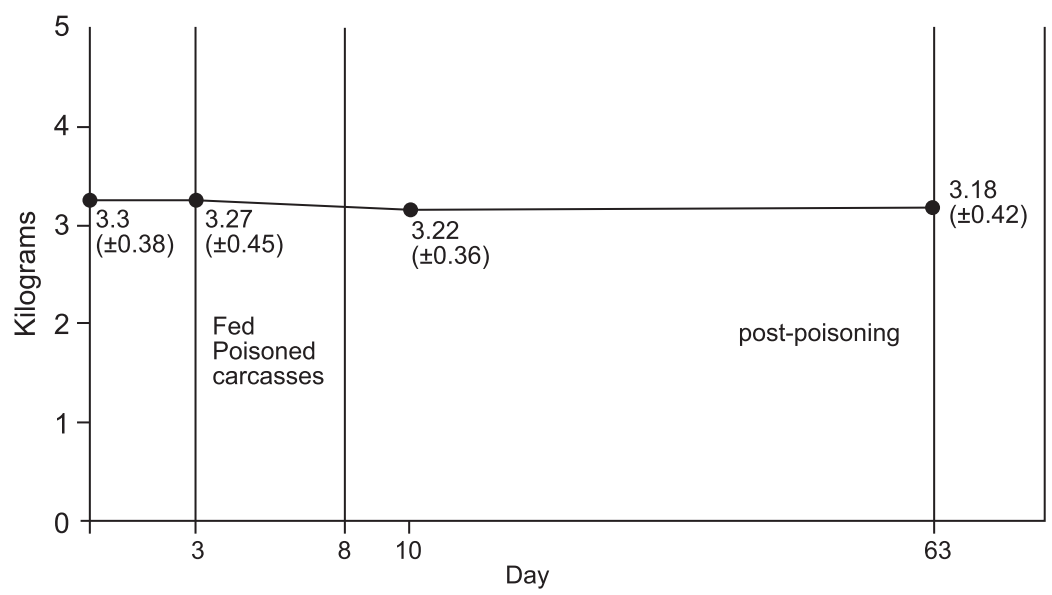

FIGURE 1: Mean body weight $(\mathrm{kg} \pm \mathrm{SD})$ in cats before, during and after feeding on the carcasses of cholecalciferol-poisoned possums. 
TABLE 2: Mean total serum calcium $( \pm \mathrm{SE})$ concentrations $(\mathrm{mmol} / \mathrm{litre})$ in cats.

\begin{tabular}{cccc}
\hline Pre-treatment & After 5 days & 1 week later & 7 weeks later \\
\hline $2.54(0.06)$ & $2.75(0.10)$ & $2.72(0.07)$ & $2.64(0.03)$ \\
\hline
\end{tabular}

Mean total serum concentrations of calcium in dogs fed daily (for 5 days) with a possum that died and dogs fed killed possums increased by a maximum of $18 \%$ and $39 \%$ respectively within a week of starting to feed on contaminated possums, and remained above the normal canine range for a further 1-2 weeks (Table 3). Mean serum urea nitrogen concentrations in dogs fed five poisoned carcasses from both the acute and chronic groups also exceeded normal values by day 4 , indicative of either toxin-induced renal damage or dehydration secondary to anorexia (Table 4). Serum urea nitrogen returned to normal by day 28 after dosing in all animals. No toxin-related changes were observed in the haematology in any treatment group, and no dogs died.

All dogs that were fed five possum carcasses from the 'acute' group exhibited partial anorexia and varying degrees of lethargy from day 4 to day 14 after dosing. By day 7 , mean body weights had decreased by $5 \%$ compared to pre-treatment values. All affected dogs began to recover without veterinary intervention or treatment by about 14 days after the onset of exposure. Appetite and body weight gradually returned to pre-treatment levels.

Histopathological examination revealed dystrophic mineralisation of the kidneys consistent with cholecalciferol toxicosis in all dogs euthanased on day 14 that had been hypercalcaemic, with the most severe lesions observed in animals fed 'acute' possums. No toxin-induced lesions were observed in dogs euthanased on day 28, possibly indicating recovery from toxin-induced renal damage.

TABLE 3: Mean ( \pm SE) total serum calcium concentrations (mmol/litre) in dogs fed possum carcasses for 5 consecutive days as a function of time after the onset of exposure ${ }^{1}$.

\begin{tabular}{ccccccccccccccc}
\multicolumn{2}{c}{ Treatment day } & day & day & day & day & day & day & day & day & day & day & day & day & day \\
& 0 & 1 & 2 & 3 & 4 & 5 & 6 & 7 & 8 & 10 & 12 & 14 & 21 & 28 \\
\hline \multirow{2}{*}{ Control } & 2.59 & 2.66 & 2.66 & 2.54 & 2.57 & 2.64 & 2.52 & 2.69 & 2.72 & 2.73 & 2.64 & 2.64 & 2.58 & 2.53 \\
& \pm 12 & \pm 16 & \pm 15 & \pm 18 & \pm 15 & \pm 19 & \pm 15 & \pm 19 & \pm 13 & \pm 11 & \pm 16 & \pm 16 & \pm 12 & \pm 18 \\
Acute & 2.75 & 2.88 & 3.02 & 3.22 & 3.50 & 3.70 & 3.53 & 3.86 & 3.59 & 3.71 & 3.30 & 3.19 & 2.63 & 2.70 \\
& \pm 11 & \pm 13 & \pm 11 & \pm 20 & \pm 22 & \pm 35 & \pm 22 & \pm 21 & \pm 26 & \pm 26 & \pm 22 & \pm 18 & \pm 19 & \pm 18 \\
Chronic & 2.76 & 2.79 & 3.02 & 2.93 & 3.16 & 3.13 & 3.09 & 3.31 & 3.16 & 3.16 & 2.94 & 2.88 & 2.74 & 2.62 \\
& \pm 09 & \pm 07 & \pm 12 & \pm 18 & \pm 27 & \pm 20 & \pm 25 & \pm 37 & \pm 18 & \pm 22 & \pm 15 & \pm 11 & \pm 09 & \pm 12
\end{tabular}

${ }^{1}$ Normal values for total serum calcium concentrations in dogs are 2.0-3.0 mmol/litre.

TABLE 4: Mean ( $\pm \mathrm{SE})$ serum urea nitrogen concentrations (mmol/litre) in dogs fed possum carcasses for 5 consecutive days as a function of time after the onset of exposure ${ }^{1}$.

\begin{tabular}{lcrrrr}
\hline Treatment & day 0 & \multicolumn{1}{c}{ day 4} & day 7 & day 14 & day 28 \\
\hline Control & $6.4 \pm 0.9$ & $6.2 \pm 0.8$ & $6.3 \pm 0.7$ & $6.0 \pm 0.8$ & $6.2 \pm 0.7$ \\
Acute & $5.6 \pm 0.8$ & $10.6 \pm 2.2$ & $11.6 \pm 2.6$ & $9.0 \pm 2.0$ & $6.7 \pm 0.8$ \\
Chronic & $6.4 \pm 0.6$ & $7.2 \pm 1.5$ & $8.4 \pm 1.9$ & $5.4 \pm 0.7$ & $6.0 \pm 0.7$
\end{tabular}

${ }^{1}$ Normal values for serum urea nitrogen in dogs are $3.6-7.8 \mathrm{mmol} / \mathrm{litre}$. 


\section{DISCUSSION}

Mallard ducks and some chickens and canaries dosed with cholecalciferol at 2000 $\mathrm{mg} / \mathrm{kg}$ survived, as did all weka eating baits containing $0.1 \%$ cholecalciferol. These results are consistent with earlier studies in ducks and quail (Marshall 1984).

A duck would only need to eat one $0.15 \% 1080$ bait $(5-10 \mathrm{~g})$ to receive a lethal dose, compared with $200 \mathrm{~g}$ of $20 \mathrm{mg} / \mathrm{kg}$ brodifacoum bait, or more than $200 \mathrm{~g}$ of $0.8 \%$ cholecalciferol (as used for possum control) or $2000 \mathrm{~g}$ of $0.08 \%$ cholecalciferol (as used for rat control). Nevertheless it is apparent that the sensitivity of different bird species to cholecalciferol varies considerably, and care must be taken to minimise exposure to birds when baiting in the field. Like brodifacoum but unlike 1080, cholecalciferol showed no insecticidal effects when weta were dosed.

Our feeding study with feral cats appeared to confirm an earlier secondarypoisoning study with dogs (Marshall 1984), which indicated that the risk of secondary poisoning with cholecalciferol is very low. However, our assessment in dogs indicates that there is a risk of hypercalcaemia and adverse effects on target organs such as the kidney in dogs repeatedly eating carcasses of animals poisoned with cholecalciferol baits.

Marshall (1984) reported no signs of cholecalciferol intoxication in dogs fed rats for 14 days, but included no data on food consumption, body weights, blood chemistry, or pathology. Hence it is not possible to compare the Marshall (1984) secondarypoisoning study with the toxicosis observed in our study. The toxicosis we observed in dogs could have been a factor of a more detailed toxicological assessment of general health, body weight, and pathology, or a result of the higher concentration of cholecalciferol $(0.8 \%)$ used in possum baits versus rodent baits $(0.075 \%)$.

Regardless of this, we can conclude that baits containing cholecalciferol have a lower risk of causing secondary poisoning of pets when compared with 1080 or brodifacoum. This is the most distinguishing feature of cholecalciferol when compared to other commonly used vertebrate pesticides. However, low risks of secondary poisoning with cholecalciferol does not imply no risk, and all pets and farm dogs should be discouraged from eating animals that have been poisoned with cholecalciferol. Since we have shown that mild toxicosis can occur in dogs eating possum meat, it would be extremely unwise for hunters to take game from areas where cholecalciferol has been used in the last 1-3 months. The potential hazard to humans would be exacerbated if game species gain direct access to bait.

Persistence studies with cholecalciferol indicate that elevated concentrations of 25OHD are likely to persist for several weeks in possums that receive sub-lethal doses (Eason et al. 1996a) and similar persistence may be anticipated in feral game species if they consume bait. In comparison to other examples in the literature, the clearance of elevated 25OHD in poisoned possums appeared to be quite slow. This is perhaps not surprising since it has been shown in other animals that clearance of 25OHD is dose-dependent (Keiver et al. 1988), and target animals poisoned with cholecalciferol received extremely high near-lethal doses. For example, the plasma elimination halflives of 25OHD were 15-36 days in humans when vitamin D status was normal, but increased to 25-68 days in humans and cows experiencing vitamin D toxicosis (Keiver et al. 1988). Clearly 25OHD is more persistent than rapidly eliminated poisons like 1080 (Eason et al. 1996a), but is less persistent than second-generation anticoagulants like brodifacoum (Eason et al. 1996b). Research in rats has demonstrated that 25OHD, whilst active when administered orally (Rambeck et al. 1990), is partially degraded in the intestinal tract (Frolick and Deluca 1973). Hence not all the 25OHD present in poisoned carcasses will be bioavailable to animals eating poisoned carcasses. At present there are no data on the persistence of cholecalciferol in the carcasses of dead possums.

\section{ACKNOWLEDGEMENTS}

The authors would like to thank Andrea Rhodes for assistance in the conduct of the study; Eric Spurr, Dave Morgan, Louis Tremblay and Oliver Sutherland for their comments on the manuscript; and Christine Bezar, Bruce Chapman and Sue Zydenbos for editing. The Animal Health Board supported these hazard assessment studies. 


\section{REFERENCES}

Beard, M.L., Montman, C.E., Maupin, G.O., Barnes, A.M., Craven, R.B. and Marshall, E.F., 1988. Integrated Vector Control Rodenticide may reduce the spread of human plague. J. Environ. Health 51(2): 69-75.

Beasley, V.R., Dorman, D.C., Fikes, J.D., Diana, S.G. and Woshner, V., 1997. Cholecalciferol-based rodenticides and other vitamin D-containing products. $\mathrm{Pp}$ 445-450 In: A systems affected approach to veterinary toxicology. University of Illinois Press, Urbana, Illinois, USA.

Dougherty, S.A., Center, S.A. and Dzaris, D.A., 1990. Salmon calcitonins as an adjunct treatment for vitamin D toxicosis in a dog.J. Am. Vet. Med. Assoc. 196(8): $1269-1272$.

Eason, C.T., 1991. Cholecalciferol as an alternative to sodium monofluoroacetate (1080) for poisoning possums. Proc. 44th N.Z. Weed and Pest Control Conf: : 35-37.

Eason, C.T., 1993. The acute toxicity of cholecalciferol to the European rabbit, Oryctolagus cuniculus. Wildlife Res. 20: 173-176.

Eason, C.T. and Spurr, E., 1995. Review of the toxicity and impacts on non-target wildlife in New Zealand. N.Z. J. Zool. 22: 371-379.

Eason, C.T., Henderson, R., Thomas, M.D. and Frampton, C.M., 1994. The advantages and disadvantages of sodium monofluoroacetate and alternative toxins for possum control. Pp 159-166 In: Proceedings of the science workshop on 1080. A.A. Seawright and C.T. Eason (Eds). Royal. Soc. N.Z. Misc. Series 28.

Eason, C.T., Wright, G.R., Meikle, L. and Elder, P., 1996a. The persistence and secondary poisoning risks of sodium monofluoroacetate (1080), brodifacoum, and cholecalciferol in possum. Proc. 17th Vertebr. Pest Conf.: 54-58.

Eason, C.T., Wright, G.R. and Batcheler, D., 1996b. Anticoagulant effects and persistence of brodifacoum in possums (Trichosurus vulpecula). N.Z. J. Agric. Res. 39: 397-400.

Frolick, C.A. and Deluca, H.F., 1973. The stimulation of 1,25-dihydrocholecalciferol metabolism in vitamin D-deficient rat by 1,25 -dihydrocholecalciferol treatment. J. Clin. Invest. 52: 543-548.

Gunther, R., Felice, L.J. and Nelson, R.K., 1988. Cholecalciferol rodenticide toxicity. J. Am. Vet. Med. Assoc. 193: 211-214.

Haschek, W.M., Krook, L., Kallfelz, F.A. and Pond, W.G., 1978. Vitamin D toxicity initial site and mode of action. Cornell Veterinarian 68: 324-334.

Henderson, R.J., Frampton, C.M., Thomas, M.D. and Eason, C.T., 1994. Field evaluation of cholecalciferol, gliftor and brodifacoum for the control of brushtailed possums. Proc. 47th N.Z. Plant Prot. Conf:: 112-117.

Jolly, S.E., Eason, C.T. and Frampton, C., 1993. Serum calcium levels in response to cholecalciferol and calcium carbonate in the Australian brushtailed possum. Pestic. Biochem. Physiol. 47: 159-164.

Jolly, S.E., Henderson, R.J., Frampton, C. and Eason, C.T., 1995. Cholecalciferol toxicity and its enhancement by calcium carbonate in the common brushtail possum. Wildlife Res. 22: 579-583.

Keiver, K.M., Draper, H.H. and Ronald, K., 1988. Vitamin D metabolism in the hooded seal (Crystophore cristatra). J. Nutr. 118: 332-341.

Marshall, E.F., 1984. Cholecalciferol: a unique toxicant for rodent control.Proc. 11th Vertebr. Pest Conf:: 95-98.

Moore, F.M., Kudisch, M., Richter, K. and Faggella, A., 1988. Hypercalcemia associated with rodenticide poisoning in three cats. J. Am. Vet. Med. Assoc. 193: 1099-1110.

Pospischil, R. and Schnorbach, H.J., 1994. Racomin plus ${ }^{\circledR}$, a new promising rodenticide against rats and mice. Proc. 16th Vertebr. Pest Conf:: 180-187.

Rambeck, W.A., Schafer, B., Hanichin, T. and Zucker. H., 1990. Vergloichende Kalzinogenitat von Vitamin $\mathrm{D}_{3}$ and Vitamin $\mathrm{D}_{2}$ Metabollen beim. Kaninchem. Sonderdruk 45(10): 739-743.

Tobin, M.E., Matschke, C.H., Sugihara, R.T., McCann, C.R., Koehler, A.E. and Andrews, K.T., 1993. Laboratory efficacy of cholecalciferol against field rodents. USDA Animal and Plant Health Inspection Services DWRS Research Report No.11-55-002. p.15. 